\title{
Early retinal changes after uncomplicated mild and hard cataract surgery
}

\author{
Özkan Sever ${ }^{1^{*}}$ and Fatih Horozoğlu ${ }^{2}$ \\ Department of Ophthalmology, Namik Kemal University, Faculty of Medicine, Tekirdag
}

\begin{abstract}
To evaluate and compare the possible effects of hard and soft nuclear cataract surgeries in the development of early postoperative retinal complications.

In a retrospective study design 1388 uncomplicated phacoemulsification surgery were enrolled in the study. Data for 688 Grade 5-6 and 700 Grade 2-3 nuclear cataracts according to Lens Opacities Classification System III (LOCS III) were used for comparison. All patients were evaluated for visual acuity (VA), intraocular pressure (IOP), central macular pathologies and angiographic fluid leakage pattern at 1 week and 1 month. Biomicroscopic evaluation, optical coherence tomography (OCT), fleuroscein angiography (FA) and indocyanine green angiography (ICG) were used for examination.

Follow up time was 1 month. Mean CMT of patients were higher at hard cataracts but not statistically significant $(\mathrm{p}>0.24)$. Clinically significant cystoid macular edema after hard nuclear cataract surgery was $1.59 \%(11)$ and $1.28 \%(9)$ for soft cataracts ( $p>0.05)$. After $20 / 20$ visual acuity at 1 week, $5(0.72 \%)$ patients from hard nuclear group had visual loss and hemorrhagic pigment epitelial detachment (PED) at 1 month control. Angiographic evaluations revealed them 4 as insignificant polypoid choroidal vasculopathy (PCV). One of them is still controversial. IOP and VA results were similar at both controls $(\mathrm{p}>0.05)$.

Subretinal hemorrhage after cataract surgery may be the first sign of some PCV patients. Patients who were diagnosed with PCV should be carefully evaluated for cataract surgery. Hard nuclear cataract may be a predisposing factor for early hemorhagic PED in patients with PCV. Any retinal pathology should be carefully evaluted before cataract surgeries.
\end{abstract}

Key Words: Cataract, polypoidal choroidal vasculopathy, hemorrhagic pigment epithelial detachment

\section{Introduction}

It could be safely assumed that as the society gets older the number of cataract patients increase (1). According to 2010 National Eye Institute (NEI) records number of cataract patients in the U.S is expected to be doubled from 24.4 million to about 50 million by 2050 . Such an increase will bring a higher demand for cataract surgery. Today it is widely accepted that the most frequent surgical method which is used for cataract surgery is phacoemulsification (2). Cataract surgery complications are mainly posterior capsular rupture and vitreous loss, vitreous prolapse, expulsive haemorrhage, Descemet's membrane detachment, intraocular haemorrhage, wound malposition, shallow anterior chamber, iris prolapse, infectious endophthalmitis, corneal oedema, dropped nucleus or retained nuclear fragments, cystoid macular oedema, retinal detachment, posterior capsule opacification $(3,4)$. The nature of cataract itself also effects the results of surgery. In eyes with hard nuclear cataract, the total ultrasound time and cumulative dissipated energy (mean percentage of ultrasound power) during phacoemulsification surgery increases as well as complications (5).

In this study we aimed to evaluate and compare the early retinal complications of phacoemulsification surgery after low-density and high-density nuclear cataracts.

\section{Material and Method}

Medical records of 1388 patients who had phacoemulsification surgery at Namik Kemal University Department of Ophthalmology between November 2010 and March 2016 were reviewed. All surgeries were made at the same hospital without any intraoperative complications. Informed consent was taken from all patients. The study protocol was approved by the local ethics committee of the same university and performed according to the Declaration of Helsinki.

All patients were routinely classified in accordance with Lens Opacities Classification System III (LOCS III). A total of 688 hard nuclear cataracts (Grade 5-6) and 700 soft nuclear cataracts (Grade 2-3) were enrolled in the study. Inclusion criterias 
were; cataract formation, visual acuity (VA) lower than 5/10 Snellen, Endothelial Cell Density (ECD) higher than 1500 cells $/ \mathrm{mm} 2$. Exclusion criterias were uncontrolled glaucoma, blood glucose level over $200 \mathrm{mg} / \mathrm{dl}$ (DM), active uveitis, senile macular degeneration, high myopia, hypermetropia, retina detachment and any active corneal pathology.

All patients had complete ophthalmic examination including slit-lamp microscopic evaluation, intraocular pressure measurement (Goldmann Applanation Tonometry), central corneal thickness (CCT) measurement (Pascan 300P,Sonomed,Inc.), VA (with snellen chart) before operations and postoperative 1 day, 1 week and 1 month. Those patients with early retinal complications were evaluated with Fluorescein angiography (FA), indocyanine green angiography (ICGA) and Optical Coherence Tomography (OCT) (Cirrus HD-OCT,Carl Zeiss Ophthalmic System Inc, Zeiss-Humphrey, Dublin, California, USA).

Before operations 3 times at 5 minutes intervals propacaine hydroclorur was dropped for local anesthesia. $2.8 \mathrm{~mm}$ clear corneal incisions were made superotemporally and $220-G$ MVR incision on 10 and 4 o'clock. Continuous capsulorrhexis at least $6 \mathrm{~mm}$ was achieved and after hydrodissection the standard surgery used for groups was torsional quick chop method (Ozil IP, Alcon Laboratories, Inc.). Cortex and viscoelastics were cleaned by irrigation $\backslash$ aspiration cannula (Alcon Lab.). Corneal endothelial protection was achieved by Ophthalmic Viscoelastic Device (OVD) (sodium hyaluronate [Microvisc 1.4\%]. All incision places were closed with stromal hydration and moxifloxacin was administered to anterior chamber. Topical moxifloxacin and prednisolone acetonide were reciped for at least 2 weeks 4 times a day.

Statistical Analysis: The data were analyzed with SPSS for Windows, version 18.0; IBM-SPSS, Chicago, Illinois, USA. Distribution analysis were made with Kolmogrov-Smirnov tests. MannWhitney $\mathrm{U}$ tests were used to compare the groups.

\section{Results}

No complications occurred during surgeries. Follow up time was 1 month. (Table 1) shows all patient characteristics.

Postoperative 1 week and first month mean visual acuity of groups were $0.82 \pm 0.7$ and $0.93 \pm 0.88$ for soft cataract group and $0.76 \pm 0.17$ and $0.91 \pm$ 1.1 Snellen for hard nuclear cataract group, respectively. There was no statistically significant difference in the mean VA between hard nuclear and soft nuclear cataract groups at 1 week and 1 month postoperative controls $(\mathrm{P}=0.22)$. Postoperative 1 week and first month mean central macular thickness (CMT) of groups were $243 \pm 19.1 \mu \mathrm{m}$ and $245 \pm 15.8 \mu \mathrm{m}$ for soft cataract group and $278 \pm 22.2 \mu \mathrm{m}$ and $270 \pm 17.9$ $\mu \mathrm{m}$ for hard nuclear cataract group, respectively. Mean postoperative 1 month CMT of patients were higher at high density nuclear cataract group however it was not statistically significant $(\mathrm{p}=0.24)$.

Three patients $(0.21 \%)$ had rhegmatogenous retinal detachment $(\mathrm{RD})$ at postoperative 1 week control. Two of these subjects were from the soft nuclear group with high myopia (>6D) and 1 was from the hard nuclear group without any myopia or a significant history.

Table 1. Patient Characteristics

\begin{tabular}{|c|c|c|c|}
\hline Parameters & Hard Cataracts & Soft Cataracts & $\mathrm{P}$ values \\
\hline \multicolumn{4}{|l|}{ Sex, $n$} \\
\hline Male & $258(37.5 \%)$ & $190(27 \%)$ & $\mathrm{P}=0.35$ \\
\hline Female & $430(62.5 \%)$ & $510(73 \%)$ & $\mathrm{P}=0.51$ \\
\hline $\mathrm{IOP}, \mathrm{mmHg}$ & $17.6 \pm 3.3$ & $14.4 \pm 2.9$ & $\mathrm{P}=0.64$ \\
\hline CCT & $535 \pm 13.2$ & $549 \pm 18.1$ & $\mathrm{P}=0.81$ \\
\hline \multicolumn{4}{|l|}{ Age } \\
\hline Mean \pm SD & $69.4 \pm 11.5$ & $71.7 \pm 8.2$ & $\mathrm{P}=0.9$ \\
\hline Range & 50,85 & 54.84 & $\mathrm{P}=0.48$ \\
\hline $\mathrm{VA} \pm \mathrm{SD}$, Snellen & $0.14 \pm 0.11$ & $0.19 \pm 0.23$ & $\mathrm{P}=0.24$ \\
\hline Hypertension, $\mathrm{n}$ & $132(19.1 \%)$ & $105(15 \%)$ & $\mathrm{P}=0.26$ \\
\hline Diabetes Mellitus, $\mathrm{n}$ & $58(8.4 \%)$ & $79(11.2 \%)$ & $\mathrm{P}=0.37$ \\
\hline Systemic Steroid Use, $\mathrm{n}$ & $9(1.3 \%)$ & $24(3.4)$ & $\mathrm{P}=0.19$ \\
\hline
\end{tabular}

VA, visual acuity IOP, intraocular pressure $S D$, standat deviation $\mathrm{D}$, diyopter, $\mathrm{p}>0,05$ is insignificant 
Number of clinically significant pseudophakic cystoid macular edema (PCME) after hard and soft nuclear cataract surgeries were $11(1.59 \%)$ and $9(1.28 \%)$, respectively $(p=0.52)$. Eight out of 20 patients with PCME were diabetic and 12 $(60 \%)$ of them were male.

After near $20 / 20$ visual acuity at 1 week, 5 $(0.72 \%)$ patients from hard nuclear group had visual loss and hemorrhagic pigment epithelial detachment (PED) until 1 month control. VA of the patients with PED varied between hand motions to 1 meter finger counting. Figure 1 shows fundus photographs of a patient with hemorrhagic PED. Patients underwent OCT, FA and ICGA. Evaluations revealed them 4 as polypoid choroidal vasculopathy (PCV). One of them is still controversial because of massive subretinal hemorrhage and low vision patient didn't follow the visits. Two paients had systemic hypertension, 1 patient had astma and one was an obese woman. Almost all patients were smoking cigarette. Table 2 shows all clinical characteristics of patients with hemorrhagic PED.
IOP results were similar at both controls $(\mathrm{p}>0.05)$. Table 3 shows general postoperative complications of groups.

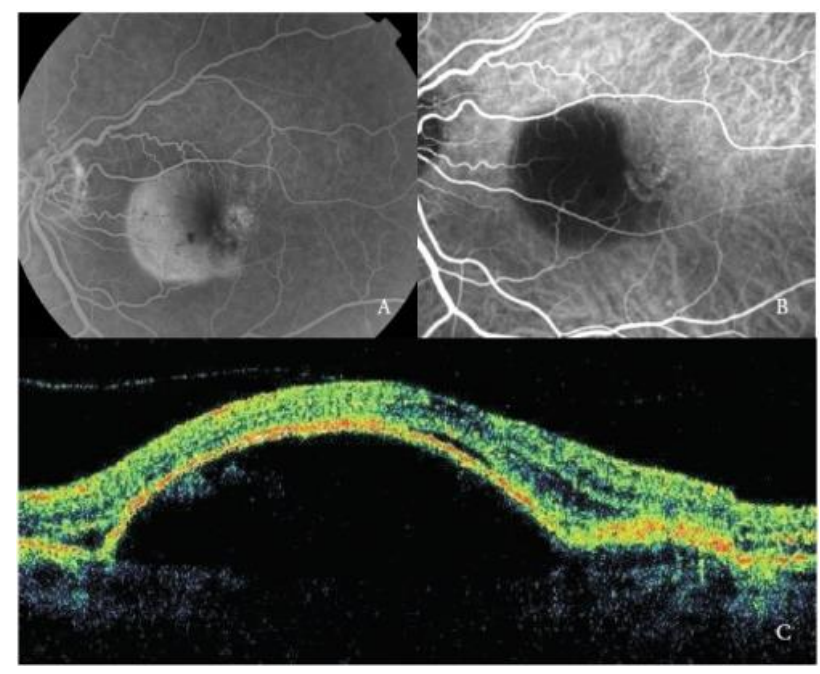

Fig. 1. Fundus photography, optical coherence tomography and angiography findings of a patient with hemorrhagic pigment epithelial detachment.

Table 2. Clinical Characteristics of Patients Who Developed Postoperative Hemorrhagic Pigment Epithelial Detachment

\begin{tabular}{|c|c|c|c|c|c|c|c|c|c|c|}
\hline $\begin{array}{l}\text { Patients, } \\
\mathrm{n}\end{array}$ & Age & Sex & $\begin{array}{l}\text { VA(Before } \\
\text { Hemorrhage) }\end{array}$ & $\begin{array}{l}\text { VA(After } \\
\text { Hemorrhage) }\end{array}$ & $\begin{array}{l}\text { PCV } \\
\text { Location }\end{array}$ & $\begin{array}{l}\text { Duration } \\
\text { Untill } \\
\text { Postoperative } \\
\text { Hemorrhage }\end{array}$ & $\begin{array}{l}\text { Systemic } \\
\text { Diseases }\end{array}$ & Drugs & $\begin{array}{l}\text { Preoperative } \\
\text { eye } \\
\text { disorders }\end{array}$ & $\begin{array}{l}\text { Cigarette } \\
\text { Smoking, } \\
\mathrm{n} \backslash \text { day }\end{array}$ \\
\hline 1 & 68 & Male & $20 / 20$ & $10 \mathrm{~cm}$ & Juxtafoveal & 10 days & Hypertension & B-Blocker & None & 20/day \\
\hline 2 & 57 & Male & $18 / 20$ & $1 \mathrm{~m}$ & $\begin{array}{l}\text { Juxtafoveal+ } \\
\text { Subfoveal }\end{array}$ & 14 days & Hypertension & $\begin{array}{l}\text { B- } \\
\text { Blocker+ACE } \\
\text { inhibitor }\end{array}$ & Myopia 5 D & $30 /$ day \\
\hline 3 & 55 & Female & $18 / 20$ & $1 \mathrm{~m}$ & Juxtafoveal & 11 days & None & None & None & $5 /$ day \\
\hline 4 & 69 & Male & $20 / 20$ & $50 \mathrm{~cm}$ & Subfoveal & 18 days & Asthma & $\begin{array}{l}\text { Ventolin } \\
\text { inhaler }\end{array}$ & none & 10/day \\
\hline 5 & 74 & Male & $16 / 20$ & $\mathrm{HM}$ & $?$ & 8 days & Obesity & None & Myopia 4 D & none \\
\hline
\end{tabular}

VA, visual acuity PCV, polypoidal vascular chorioretinopathy HM, Hand Motions D, diyopter

Table 3. Postoperative early retinal complications

\begin{tabular}{llll}
\hline & $\begin{array}{l}\text { Hard } \\
\text { Cataracts }\end{array}$ & $\begin{array}{l}\text { Soft } \\
\text { Cataracts }\end{array}$ & P value \\
\hline Retina Detachment & $1(0.14 \%)$ & $2(0.28 \%)$ & $\mathrm{p}>0.05$ \\
\hline Endophthalmitis & None & None & \\
\hline CME, $\mathrm{n}$ & $11(1.59 \%)$ & $9(1.28 \%)$ & $\mathrm{p}=0.52$ \\
\hline Hemorrhagic PED, $\mathrm{n}$ & $5(0.72 \%)$ & None & $\mathrm{P}=0.18$ \\
\hline
\end{tabular}

CME, cystoid macular edema PED, pigment epithelial detachment.

\section{Discussion}

Cataract is the foremost cause of preventable blindness and phacoemulsification. Surgery is the most common operation performed worldwide
(6). To our knowledge PCME is the most frequent early postoperative retinal complication which result in impaired VA (7). Incidence of PCME in previous studies varies between $0.1 \%$ to $2.35 \%$ (8). In the studies intraoperative complications (vitreous loss etc.), male sex and diabetes mellitus are implicated as risk factors for PCME (9). In accordance with the studies mentioned above, the mean PCME in our patients was $1.44 \%$ and $60 \%$ were male, $40 \%$ were diabetic. There was no significant difference between high density and low density nuclear cataract groups $(\mathrm{p}=0.52)$.

$\mathrm{RD}$ is one of the leading sight-threatening complication of phacoemulsification surgery and complicates almost $1 \%$ of all operations performed in the developed countries (10). Mainly 
three risk factors are implicated, 1-Patient factors (long axial length etc.), 2-Surgical factors (vitreous loss, and posterior capsule rupture etc.) and 3Postoperative factors ( $\mathrm{Nd}: \mathrm{YAG}$ laser posterior capsulotomy). In a multicentered study median time to RD after cataract surgery was defined as 11 months (range, $0-8.4$ years) (11). In our study the $\mathrm{RD}$ rate was $0.21 \%$ (3 of 1688 ) by the $1^{\text {st }}$ month. High myopia in two of our RD patients were implicated as patient dependent risk factor since there was no intraoperative complications.

Endophthalmitis is a very rare but devastating complication of cataract surgery, with a reported incidence of $0.04 \%$ to $0.41 \%$ (12). Diabetes, vitreous loss, extracapsular cataract extraction and older age are implicated for endophthalmitis after cataract surgery (13). All our patients had conventional phacoemulsification method without any complication. Surgeries of patients who had uncontrolled blood sugar levels were postponed until blood sugar regulation. Thus none of our patients in neither group experienced endophthalmitis.

The term PCV is used to distinguish a specific subtype of neovascular macular degeneration. The disease is characterized with polypoidal choroidal grape-like vascular lesions (14). The prevalance of PCV is as high as up to $55 \%$ in newly diagnosed wAMD in Asian society (15). However the data on epidemiology of PCV and confidential prevalence from population based studies are been difficult because of difficulty of diagnosing the condition without ICGA. Turkey is a bridge between Asia and Europe and there is still no population based study on PCV. The risk factors for PCV formation mainly comprises; male gender, genetical factors, cigarette smoking and DM (16.17). Cackett et al. (18) reported that patients who smoked were fourfold more likely to have PCV than normal subjects. Sometimes these polyps progress to hemorrhagic complications in the subretinal pigment epithelial space and results in hemorrhagic PED. In a retrospective study reported by Cho et al. (19) $5(8,6 \%)$ of 56 eyes who had received intravitreal ranibizumab $0,5 \mathrm{mg}$ for PCV developed postoperative subretinal hemorrhage (19). In this study the mean time to postoperative hemorrhagic PED was $2.8 \pm 0.4$ days (range, 2 to 6 days) and the most possible mechanism blamed for postoperative hemorrhagic complications of PCV is retina pigment epithelial tear.

This study is the first study to show and compare the hemorhhagic PED after soft and hard nuclear cataract surgeries. Five $(0.72 \%)$ patients from high density nuclear cataract group had postoperative hemorrhagic PED while none of the patients from soft nuclear cataract group experienced hemorrhagic PED. One patient had massive subretinal hemorrhage and did not come to the visits. Four of the patients had juxtafoveal (3) and subfoveal (1) PCV. But we did not know preoperative PCV numbers in the patient population and this produces bias in our study.

Unlike the studies mentioned above mean duration to PED formation was 10.4 \pm 1.8 (8-18 day) in our study. This might lead us to think that the process is not only related with mechanical stress but also with local inflammation. In terms of local inflammation, longer ultrasonic phaco power used in hard nuclear cataracts might be a reason of greater local inflammation. This local inflammation might increase the choroidal blood flow in the fragile vessels and cause a subretinal hemorrhage. Four of the patients with hemorrhagic PED were smoking cigarette, which is thought to be one of the major risk factors in PCV formation by means of systemic inflammation (17). Two of the patients had systolic hypertension (HT) and one patient had asthma. However the previous studies couldn't find a relation between HT and PCV formation they might increase intravascular pressure and cause hemorrhage in weak vessels.

In conclusion, patients who were diagnosed with PCV should be carefully evaluated for cataract surgery. Cataract surgery increases intraocular inflammation and many studies revealed that phacoemulsification surgery is one of the causes of age related macular degeneration. It is logical that increased surgery time and inflammation increases these effects. We focused on hemorrhagic PED in patients after cataract surgery and results were as expected. Hard nuclear cataract surgery with coexisting systemic diseases might augment early hemorhagic PED in patients with PCV.

Conflict of interest: None of the authors has any financial or proprietary interest.

Acknowledgement: Authors certify that the work submitted to The EASTERN JOURNAL OF MEDICINE has not been published elsewhere, in any form and that it is not being submitted simultaneously to another journal.

\section{References}

1. Klein BE, Klein R, Lee KE. Incidence of agerelated cataract over a 15 -year interval the Beaver 
Dam Eye Study. Ophthalmology 2008; 115: 477 482.

2. Leaming DV. Practice styles and preferences of ASCRS members--1994 survey. J Cataract Refract Surg 1995; 21: 378-385.

3. Gonen T, Sever O, Horozoglu F, Yasar M, Keskinbora KH. Endothelial cell loss: Biaxial small-incision torsional phacoemulsification versus biaxial small incision longitudinal phacoemulsification. J Cataract Refract Surg 2012; 38: 1918-1924.

4. Dushku N, John MK, Schultz GS, Reid TW. Pterygia pathogenesis: corneal invasion by matrix metalloproteinase expressing altered limbal epithelial basal cells. Arch Ophthalmol 2001; 119: 695-706.

5. Bozkurt E, Bayraktar S, Yazgan S et al. Comparison of conventional and torsional mode (OZil) phacoemulsification: randomized prospective clinical study. Eur J Ophthalmol 2009; 19: 984-989.

6. Pascolini D, Mariotti SP. Global estimates of visual impairment: 2010. Br J Ophthalmol 2012; 96: 614-618.

7. Kim SJ, Schoenberger SD, Thorne JE. Topical nonsteroidal anti-inflammatory drugs and cataract surgery: a report by the American Academy of Ophthalmology. Ophthalmology 2015; 122: 21592168 .

8. Loewenstein A,Zur D.Postsurgical cystoid macular edema.Dev Ophtalmol 2010; 47: 148519.

9. Chu C, Johnston R, Buscombe C. Risk Factors and Incidence of Macular Edema After Cataract Surgery:A Database Study of 81984 Eyes. Ophthalmology, Vol. 2, p316-323.

10. Erie JC, Raecker MA, Baratz KH, Schleck CD, Burke JP, Robertson DM. Risk of retinal detachment after cataract extraction, 1980-2004: a population-based study. Ophthalmology 2006; 113: 2026-2032.
11. Antony Clark, Nigel Morlet, Jonathon Q. Ng, David B. Preen, James B. Semmens.Risk for Retinal Detachment After PhacoemulsificationA Whole-Population Study of Cataract Surgery Outcomes. Arch Ophthalmol 2012; 130: 882-888.

12. Miller JJ, Scott IU, Flynn HW Jr. Acuteonsetendophthalmitis after cataract surgery (2000-2004);incidence,clinical settings, and visual acuity outcomes after treatment.Am J Ophthalmol 2005; 139: 983-987.

13. Jabbarvand M, Hashemian H, Khodaparast M . Endophthalmitis Occuring After Cataract Surgery: Outcomes of more than 480000 Cataract Surgeries, Epidemiologic Features and Risk Factors. 2016; 123: 295-301.

14. Yannuzzi LA, Sorenson J, Spaide RF, Lipson B. Idiopathic polypoidal choroidal vasculopathy (IPCV). Retina 1990; 10: 1-8.

15. Cheung CM, Yang E, Lee WK, et al. The natural history of polypoidal choroidal vasculopathy: a multi-center series of untreated Asian patients. Graefes Arch Clin Exp Ophthalmol 2015; 253: 2075-2085.

16. Woo S.J, Ahn J, Morrison M.A, et al. Analysis of genetic and environmental risk factors and their interactions in korean patients with age-related macular degeneration. PLoS One 10, 2015 e0132771.

17. Sakurada Y, Yoneyama S, Imasawa M, Iijima $H$. Systemic risk factors associated with polypoidal choroidal vasculopathy and neovascular age related macular degeneration. Retina 2013; 33: 841-845.

18. Cackett P, Yeo I, Cheung CM et al. Relationship of smoking and cardiovascular risk factors with polypoidal choroidal vasculopathy and age-related macular degeneration in Chinese persons. Ophthalmology 2011; 118: 846-852.

19. Cho HJ, Lee DW, Cho SW, Kim CG, Kim JW. Hemorrhagic complications after intravitreal ranibizumab injection for polypoidal choroidal vasculopathy. Can J Ophthalmol 2012; 47: 170 175. 